Derivatives:

Phenyl osazone was prepared in ordinary way. Recrystallized from 10 $\%$ alcoholic solution, $\mathrm{mp} 192^{\circ}$ (yellow needle), $p$-brom-o-phenylosazone was also prepared. To $0.3 \mathrm{~g} \cdot \mathrm{p}$-brom-o-phenylhydrazine in 3 c.c. hot water was added $0.1 \mathrm{~g}$. sugar dissolved in 0.5 c.c. water and 1 c.c. of $50 \%$ aqueous acetic acid, and the mixture was heated on water-bath for 10 minutes. On cooling, the crystals separated out which recrystallized from $50 \%$ alcoholic solution form yellow needles of $\mathrm{mp} 162^{\circ}$.

The aqueous sugar solution is dextrorotatory:

These results indicate that the carbohydrate is a pentose and attached to cyanidin in molecular proportion, but further investigation is required in these respects.

\title{
The Catechin in the Fruit of Areca catechu L.
}

\author{
By \\ Ryo Yamamoto and Tosiro Muraoka. \\ (Agricultural Chemical Department, Taihoku Imperial University, Taiwan, Japan.)
}

(Received August 16, 1932.)

According to A. G. Perkin ${ }^{(1)}$ areca catechin seems to resemble acacia catechin, but its pure isolation has not yet been succeeded. The fresh pulp of the fruit is colourless and soluble in water, but when it is dried in air it becomes insoluble brown matter, having an appearance of a phlobaphene. The fresh pulp must, therefore, be taken for a starting material.

The attempt of the isolation of catechin from the fresh fruit was successful. The crystal we had obtained was colourless needles $\mathrm{mp} 96^{\circ}$ (the anhydrous form $\mathrm{mp} 175^{\circ}$ ). The analytical results agreed with $\mathrm{C}_{15} \mathrm{H}_{14} \mathrm{O}_{6}$, and its optical properties and its penta-acetyl derivative $\left[\mathrm{C}_{15} \mathrm{H}_{9} \mathrm{O}\left(\mathrm{OCOCH}_{3}\right)_{0}\right]$ identity with $d$ catechin which we had isolated from gambier catechu(i)(:).

\section{Experimental.}

The mashed pulp from $800 \mathrm{~g}$. fresh fruit was extracted twice with each

(1) A. G. Perkin: The Natural Organic Culouring Matters, 463.

(2) A. G. Perkin and E. Yoshitake: J. Chem. Soc., 81 (1902), 1160.

(3) Freudenberg and Purrmann: Ann. Chem., 437 (1924), 274 
$1 \mathrm{~L}$. alcohol $(94 \%)$ for two hours at $80^{\circ}$. The united filtrate was evaporated in vacuum in the atmosphere of carbon dioxide, and the catechin was precipitated as lead salt, the latter having decomposed by sulphuretted hydrogen. The filtrate from lead sulphide was concentrated in vacuum to a syrup, which was then extracted with ether using a separating funnel. The ethereal solution was then concentrated and extracted with a little water. When this water solution was cooled, needle crystals separated, melting at $96^{\circ}$. The crystals contain $4 \mathrm{~mol}$ crystalline water to be dehydrated in vacuum at $100^{\circ}$. The anhydrous substance melted at $175^{\circ}$. Yield was $3 \mathrm{~g}$.

With ferric chloride it gives a green colour, with bromine water a yellowish and with lime water a brownish red precipitate. It is precipitated when kept in contact with air, and other properties showed perfectly that it is identical with $d$-catechin from gambier.

Crystalline water:

$1.0036 \mathrm{~g}$. air-dried material lost at $100^{\circ}$ in vacuum $0.2060 \mathrm{~g}$.

$$
\begin{array}{ccc}
\text { in weight } & \mathrm{H}_{2} \mathrm{O} & 20.52 \% \\
\mathrm{Cal} . \mathrm{C}_{15} \mathrm{H}_{14} \mathrm{O}_{6} \cdot 4 \mathrm{H}_{2} \mathrm{O} & \mathrm{H}_{2} \mathrm{O} & 19.89 \%
\end{array}
$$

Analytical results :

\begin{tabular}{c|c|c|c|c}
\hline \hline Substance (mg.) & $\mathrm{H}_{2} \mathrm{O}$ (mg.) & $\mathrm{CO}_{2}$ (mg.) & $\mathrm{H} \%$ & $\mathrm{C} \%$ \\
\hline 5.219 & 2.014 & 11.887 & 4.32 & 62.13 \\
2.982 & $\mathbf{1 . 0 7 8}$ & 6.836 & 4.42 & 62.53 \\
\hline \multicolumn{2}{c}{} & & 4.82 & 62.07 \\
\hline
\end{tabular}

The rotation of $d$-catechin from areca cateclu:

$0.3125 \mathrm{~g}$. was dissolved in 25 c.c. water containing a little aceton.

$$
[\alpha]_{\mathrm{D}}^{19}=\left(+0.20^{\circ} \times 25\right):(1 \times 1.25)=+16.0^{\circ}
$$

The absorption bands of spectrum were just the same as that of $d$-catechin from gambier.

Acetyl derivative :

$0.5 \mathrm{~g}$. dried material was dissolved in 7 c.c. well cooled pyridine, acetylated by 7 c.c. of acetylchloride. The mixture was then poured into ice-water and the precipitate was crystallized from alcohol acetone mixture; colourless needles, $\mathrm{mp} 128^{\circ}$, yield $0.6 \mathrm{~g}$.

The analytical results :

The material dried at $100^{\circ}$ in vacuum and analyzed.

\begin{tabular}{c|c|c|c|c}
\hline Substance (mg.) & $\mathrm{H}_{2} \mathrm{O}$ (mg.) & $\mathrm{CO}_{2}$ (mg.) & $\mathrm{H} \%$ & $\mathrm{C} \%$ \\
\hline 5.458 & 2.357 & 12.001 & 4.79 & 59.96 \\
3.119 & 1.349 & 6.858 & 4.80 & 59.96 \\
\hline
\end{tabular}


The rotation of penta-acetyl $d$-catechin from areca catechu:

$0.4446 \mathrm{~g}$. dried substance was dissolved in 25 c.c. acetylene tetrachloride. $[\alpha]_{v}^{19}=\left(+0.74^{\circ} \times 25\right):(1 \times 1.7784)=+41.6^{\circ}$.

\title{
On the Chemical Composition, especially Organic Bases of "Di-Saké".
}

\author{
By \\ Kotaro Nisfinda. \\ (Kagosilima Agricultural College, Kagoshima, Japan.) \\ (Received September 12, 1932.)
}

The "di-sake" or "di-shu" is a kind of "saké", which is alcoholic beverage peculiar to the Japanese ; and brewed in only two prefectures-Kagoshima and Miyazaki-in Japan. The annual production of "di-saké" in these districts amounts to about 3,400 3,600 koku or $6,200 \sim 6,500$ hectolitres in round number. Its raw-materials, the same with "sake": that is (1) steamed rice, (2) "koji", the fungoidal mass of Aspergillus Oryzae grown on steamed rice, and (3) Water; but this steamed rice as raw-material of "di-sake"" was made by the very roughly polished rice than that of the "sake", and then the method of brewing differ from "saké".

In the case of brewing of "di-saké", using in comparatively small amount of water and large amount of aged "koji", the saccharification of mash is promoted and the fermentation controlled; and to neutralize the acids in fermented mash, wood ash is added into the mash before the press; and then new "di-sake" obtained by the press is not pasteurized.

The "di-sake" is a sweet liquor of a yellow or yellowish brown colour and of the consistency more viscous than that of ordinal "sake"; and its use is not only for drinking, but for cooking instead of "mirin".

\section{Experimental Results.}

The "di-saké" experimented with was brewed at Kagoshima City; and the analytical results of the sample are shown in the following table; 